\title{
China y la construcción de un régimen internacional de Cooperación Sur-Sur
}

\author{
China e a construção de um regime internacional \\ de cooperação Sul-Sul
}

\section{China and the construction of an international regime of South-South Cooperation}

DOI: $10.21530 /$ ci.v13n1.2018.737

Rafael Domínguez Martín¹

\section{Resumen}

El artículo analiza en perspectiva histórica el reciente proceso de construcción de un régimen internacional de Cooperación Sur-Sur (CSS). La hipótesis predictiva principal es que China está construyendo un régimen internacional de cooperación alternativo al del Comité de Ayuda al Desarrollo (CAD) de la OCDE, que, de acuerdo a una lógica de isomorfismo institucional, se sustenta en tres pilares: organizaciones internacionales de carácter financiero y político, instrumentos financieros de carácter concesional, y un sistema de monitoreo y evaluación. Como hipótesis subordinada se mantiene que, tras la experiencia fracasada de la década de 1970, el intento de construcción de un régimen internacional alternativo al del CAD, y, por tanto, un cambio de régimen, tendrá éxito esta vez por la creciente fortaleza de China como potencia ascendente en términos económicos, militares y culturales y de liderazgo político. Este nuevo régimen estará integrado por el primer pilar de las organizaciones internacionales financieras (el Banco Asiático de Inversión en Infraestructura) y políticas (la recién creada Agencia Estatal de Cooperación Internacional para el Desarrollo); el segundo pilar de la financiación ampliada del desarrollo; y el tercer pilar del sistema de monitoreo y evaluación.

Palabras clave: Transición Hegemónica; Realismo Moral; Cooperación Sur-Sur.

1 Doctor en Historia Económica, es Catedrático de Historia e Instituciones Económicas en la Universidad de Cantabria, donde dirige la Cátedra COIBA y los grupos de investigación en Desarrollo Humano y Cooperación Internacional de la misma Universidad, y en Cooperación Sur-Sur e integraciones regionales de la Red Española de Estudios del Desarrollo.

Artigo submetido em 28/11/2017 e aprovado em 13/03/2018. 


\begin{abstract}
The article analyzes in historical perspective the recent process of construction of an international regime of South-South Cooperation (SSC). The main predictive hypothesis is that China is leading the construction of an international regime cooperation as an alternative to that of the OECD Development Assistance Committee (DAC), which, according to a logic of institutional isomorphism, is based on the three-pillar sytem: international organizations of a financial and political nature, financial instruments concessional in character, and a system of monitoring and evaluation. As a subordinate hypothesis, it is maintained that, following the failed experience of the 1970s, the attempt to build an international regime alternative to that of the DAC, and hence a regime change, will succeed this time because of China's growing strengthens its role as an ascending power in economic, military and cultural terms and of political leadership. This new regime will be integrated by the first pillar of international financial organizations (the Asian Infrastructure Investment Bank) and political one (the newly State Agency for International Development Cooperation); the second pillar of an expanded development financing; and the third pillar of monitoring and evaluation system.
\end{abstract}

Keywords: Hegemonic Transition; Moral Realism; South-South Cooperation.

\title{
Resumo
}

O artigo analisa em perspectiva histórica o recente processo de construção de um regime internacional de Cooperação Sul-Sul (CSS). A principal hipótese preditiva é que a China está construindo um regime internacional de cooperação alternativa ao do Comité de Ajuda ao Desenvolvimento (CAD) da OCDE, que, de acordo com uma lógica de isomorfismo institucional, é baseado num tripé de três pilares: organizações internacionais de natureza financeira e política, instrumentos financeiros de natureza favorável, e um sistema de monitoramento e avaliação. Como uma hipótese subordinada, sustenta-se que, na sequência da experiência fracassada da década de 1970, a tentativa de construir uma alternativa de ao regime internacional do $\mathrm{CAD}$ significa, portanto, uma mudança de regime, e terá sucesso desta vez devido à crescente força da China como um poder ascendente em termos econômicos, militares e culturais e de liderança política. Este novo regime será integrado pelo pilar das organizações financeiras internacionais (o Banco Asiático de Investimento em Infraestrutura) e o político (a recém-criada Agência Estatal para a Cooperação Internacional para o Desenvolvimento); um segundo pilar do financiamento expandido do desenvolvimento; e um terceiro pilar do sistema de monitoramento e avaliação.

Palavras-chave: Transição Hegemônica; Realismo Moral; Cooperação Sul-Sul. 


\section{Introducción}

El objetivo de este artículo es analizar en perspectiva histórica el reciente proceso de construcción de un régimen internacional de Cooperación Sur-Sur (CSS). La hipótesis predictiva principal es que China está construyendo un régimen internacional de cooperación alternativo al del Comité de Ayuda al Desarrollo (CAD) de la OCDE que, de acuerdo a una lógica de isomorfismo institucional, se sustenta en tres pilares: organizaciones internacionales de carácter financiero y político, instrumentos financieros de carácter concesional (que incluyen cooperación técnica), y un sistema de monitoreo y evaluación. Como hipótesis subordinada se mantiene que, tras la experiencia fracasada de la década de 1970, el intento de construcción de un régimen internacional alternativo al del CAD y, por tanto, un cambio de régimen, tendrá éxito esta vez por la creciente fortaleza de China como potencia ascendente en términos económicos, militares y culturales y de liderazgo político en su nueva estrategia de lucha por el éxito (fenfayouwei), que sustituye a la anterior de mantener un perfil bajo (taoguangyanghui), y que cuenta con su propia elaboración teórica o ideología de legitimación (XUETONG, 2014, 2016 y 2018).

El artículo se estructura en dos partes. En la primera, se plantea el marco teórico para el análisis de las hipótesis a partir de la integración de la teoría occidental de los regímenes internacionales - aplicada críticamente a la experiencia histórica del Comité de Ayuda al Desarrollo (CAD) de la OCDE - y la teoría china del realismo moral. En la segunda parte, se aborda el reciente intento de China de construir un régimen internacional de CSS alternativo al del CAD a la luz de las lecciones del pasado durante la llamada era de Bandung. El trabajo cierra con las conclusiones.

\section{Marco teórico para superar el imperialismo epistemológico}

Un régimen internacional integra "los principios implícitos o explícitos, normas, reglas, y procedimientos de toma de decisiones en torno a los cuales convergen las expectativas de los actores en un área determinada de las relaciones internacionales" (KRASNER, 1982, p. 186, versión libre del autor)². El régimen

2 "Regimes can be defined as sets of implicit or explicit principies, norms, rules, and decision-making procedures around which actors' expectations converge in a given area of intemational relations”. La definición continúa 
internacional tiene también una definición funcionalista consistente en reducir costes de transacción involucrados en la coordinación de políticas y proveer información a los gobiernos, lo que disminuye la incertidumbre. Así, la medida del éxito de los regímenes internacionales, en tanto que entidades proveedoras de información y reductoras de costes de transacción, viene dada por la habilidad para cooperar de los países con intereses compartidos (KEOHANE, 1984).

Aunque el régimen internacional es parte del aparato teórico-ideológico del neoliberalismo institucionalista (TOKATLIAN, PARDO, 1990; SOGGE, 2009), tal constructo es compatible con el realismo de los intereses nacionales en el juego de la interdependencia compleja ${ }^{3}$. Dentro del paradigma neoliberal de la teoría de relaciones internacionales, el concepto de interdependencia se ha acomodado en los últimos años a la pérdida de hegemonía de Estados Unidos (EEUU), y ahora se habla de nuevo enfoque de interdependencia para significar las reglas y principios que gobiernan el comportamiento de los actores en el mercado global y las instituciones y políticas a nivel doméstico: desde este punto de vista, se apunta a la permanencia y relevancia del Estado-nación, que, en todo caso, afrontaría la creciente competencia en sus esfuerzos por marcar agendas y establecer reglas (FARRELL, NEWMAN, 2016). A la vez, el concepto de régimen puede servir para explicar la armonización de los comportamientos estatales, sobre la premisa de la existencia de un cierto orden o gobernanza internacional basado en la cooperación - que no excluye la existencia de discordias (KEOHANE, 1984) y que contempla las instituciones no sólo como reglas de juego sino como fuente crítica de poder asimétrico (FARRELL, NEWMAN, 2106) - para conseguir los resultados deseados en campos concretos de la actividad internacional (BARBÉ, 1989; STEINBERG, 2008).

Cualquier régimen internacional tiene dos dimensiones: una explícita, de características observables, recogida en acuerdos escritos de tipo soft law y mecanismos de gobernanza de una organización internacional que gestiona y representa dicho régimen; y otra implícita, de prácticas concretas informales, que implican "estados de aceptación de márgenes de variación tolerados, que se traducen en incumplimientos consentidos" (SOUTO, 2009, p. 33). Visto así, el

señalando: "Principies are beliefs of fact, causation, and rectitude. Norms are standards of behavior defined in terms of rights and obligations. Rules are specific prescriptions or proscriptions for action. Decision-making procedures are prevailing practices for making and implementing collective choice” (KRASNER, 1982, p. 186).

3 "International regimes should not be interpreted as elements of a new international order «beyond the nationstate». They should be comprehended chiefly as arrangements motivated by self-interest: as components of systems in which sovereignty remains a constitutive principle” (KEOHANE, 1984, p. 63). 
régimen internacional de la ayuda, denominado por sus creadores (Banco Mundial y CAD), arquitectura de la ayuda ${ }^{4}$, ha sido caracterizado como un régimen "débil y desequilibrado" (SOGGE, 2009, p. 12). Pero tal descripción no responde a la existencia de incumplimientos consentidos en las reglas (como el objetivo del 0,7\% del PNB de los países desarrollados para ayuda destinada a los países en desarrollo, que se arrastra desde 1970) o los procedimientos (desatar la ayuda, que se remonta a 1969). Se trata de que en los principios y normas (la ayuda para el desarrollo y bienestar de los países en desarrollo o la coherencia de políticas para el desarrollo) hay contradicciones insuperables con las prácticas concretas. Tales contradicciones se manifiestan en la autoayuda de los donantes (MELO, YOST, 1970a y 1970b; SOGGE, 2015) y la incoherencia sistemática de políticas (DOMÍNGUEZ, 2013), por la naturaleza misma de la ayuda como “medio para camuflar subvenciones a la exportación” (SOGGE, 2009, p. 17), y como generadora de dependencia (BODENHEIMER, 1970; DOMÍNGUEZ, 2017a) o ayuda reversa (HICKEL, 2015), que han debilitado este régimen desde el mismo momento de su nacimiento ${ }^{5}$.

El régimen internacional de la ayuda, construido como un acuerdo multilateral de club para gestionar la interdependencia (KEOHANE, NYE, 2001) entre países capitalistas desarrollados y en desarrollo (siempre que no fueran seguidores del sistema socialista de planificación centralizada), se basó en tres pilares: i) la institucionalidad financiero-política con dos organizaciones internacionales, una de membresía universal (el Grupo Banco Mundial), y otra de club (el CAD); ii) la definición del instrumento financiero de carácter concesional (AOD, que, pese al término equívoco de ayuda oficial al desarrollo, esconde una relación de dependencia crediticia) y que incluye cooperación técnica casi siempre atada; y iii) la estructura de monitoreo y evaluación de dicho instrumento al que luego se sumaría el pilar comercial, para evaluar también la coherencia de políticas. A los efectos de este trabajo, es importante señalar que la práctica evaluativa del CAD bebe del Plan Marshall (1947-1951) y su sistema de peer reviews, considerado como uno de los principales elementos que contribuyeron a su éxito, razón por la cual fue utilizado también por el Banco Mundial y luego, desde 1962, por el

4 "The set of rules and institutions governing aid flows to developing countries" (WORLD BANK, 2008, p. 1; OECD-DAC 2010, p. 8).

5 "If the principies, norms, rules, and decision-making procedures of a regime become less coherent, or if actual practice is increasingly inconsistent with principies, norms, rules, and procedures, then a regime has weakened" (KRASNER, 1982, p. 189; énfasis en el original). 
CAD (OECD-DAC, 2013). El CAD fue el comité partero de la OCDE, como heredera de la OECE (Organización Europea de Cooperación Económica), la institución multilateral encargada de coordinar las ayudas del Plan Marshall sobre la base de las evaluaciones por pares (HUTTON, 1974; EYBEN, 2013).

El otro punto importante es que la definición de la AOD vinculada al elemento de concesionalidad de los créditos (asumiendo la noción que proyectó el Banco Mundial con la sustitución de la demanda de ayuda a fondo perdido de los países en desarrollo por ayuda al desarrollo a través de la creación de su ventanilla blanda, la Asociación Internacional de Desarrollo, en 1960) se fue perfilando después de implementarse el sistema de evaluaciones. Ello resultó fruto de una ardua negociación con los países del G77 que pretendían cambiar el régimen internacional de la ayuda demandando transferencia neta de recursos en vez de créditos que en su mayor parte eran atados y, aunque en condiciones favorables (SCOTT, 2015 y 2017), con cláusulas duras de penalización por impago que multiplicarían luego la carga de la deuda, generadora de nueva dependencia (SOGGE, 2009; DOMÍNGUEZ, TEZANOS, 2012).

Según Keohane (1984), los regímenes internacionales son más fáciles de mantener que de crear, lo cual involucra la cuestión de la hegemonía. La hegemonía facilita la creación de regímenes (como los que surgieron de la Conferencia de Bretton Woods sobre estabilidad monetaria y financiera, comercio internacional y su complementario de defensa a partir de la hegemonía de EEUU), aunque el declive de la hegemonía no necesariamente supone el declive del régimen, de manera que éste puede ser mantenido incluso después de que las condiciones que facilitaron su creación hayan desaparecido (KEOHANE, 1984), en razón a distintos factores como la persistencia de intereses convergentes, la ausencia de una mejor alternativa para cooperar o la propia inercia institucional (STEINBERG, 2008).

Este último punto sirve para explicar la persistencia actual del régimen internacional de la ayuda del CAD, pese a la crisis de hegemonía de EEUU, indicada por la acentuación de su "micromilitarismo teatral" (TODD, 2003, p. 125$)^{6}$, y sus intentos de sobrevivir a base de múltiples estrategias como las tres siguientes: la ampliación del club a los proveedores emergentes (LUIJKX, BENN, 2017); la asimilación con sus prácticas de cooperación, mediante el concepto de Total Official Support for Sustainable Development (TOSSD); y el escamoteo de la

6 Una representación que "consiste en demostrar que el mundo necesita que los Estados Unidos aplasten lentamente a unos adversarios insignificantes", o también, "una acción militar y diplomática ejercida contra las no-potencias, para escenificar un simulacro de imperio" (TODD, 2003, p. 125, 176). 
coherencia de políticas para el desarrollo (supuestamente a favor de las necesidades e intereses de los países en desarrollo) y su sustitución por la coherencia de políticas para el desarrollo sostenible. Concepto este último que vuelve a la retórica de la interdependencia (de conciliación de intereses) con la que el G7 atacó el intento del G77 de cambiar las reglas de juego en la década de 1970, arrinconando de paso el principio de responsabilidades compartidas pero diferenciadas que reclamaron los países del G77 + China desde 1992 (DOMÍNGUEZ, 2013 y 2016a; BESHARATI, 2017; CHATURVEDI, CHAKRABARTI, SHIVA, 2016).

Una segunda proposición útil para el estudio que nos ocupa es que "la creación de nuevos regímenes internacionales puede ser facilitada por la confianza mutua creada por los viejos. Los regímenes raramente emergen del caos; por el contrario, se construyen uno sobre el otro" (KEOHANE, 1984, p. 79, versión libre del autor $)^{7}$. Esta última afirmación apoya la hipótesis del isomorfismo de la sociología de las organizaciones y las lógicas institucionales (DIMAGGIO, POWELL, 1983; FEJERSKOV, 2016), que sostiene la existencia de cambios incrementales path dependent, y permite explicar tanto los intentos de creación de una OCDE del Sur en la década de 1970, paralelos a la creación de un Banco para los Países en Desarrollo, como la arquitectura financiera que ahora, ya bajo el liderazgo que ejerce China arropada por los otros BRICS en el G77, ancla el pilar fundamental (que es de carácter financiero) de lo que más pronto que tarde acabará constituyendo un régimen internacional de CSS con su sistema de monitoreo y evaluación propio ${ }^{8}$.

Es importante subrayar, por ello, la diferencia que establece Krasner (1982) entre cambios dentro del régimen internacional y cambio del régimen internacional. En el primer caso, se trata de cambios que afectan a las reglas y procedimientos de decisión, como los que actualmente está llevando a cabo el CAD a través de la modernización de la AOD, incluido el concepto transformista de TOSSD y el ansioso proceso de ampliación del club - complementario del TOSSD - para ganar una más que improbable legitimidad a través de la interpuesta Alianza Global para la Cooperación Eficaz al Desarrollo (DOMÍNGUEZ, 2014; BESHARATI, 2017; CHATURVEDI, CHAKRABARTI, SHIVA, 2016). En el segundo caso, el cambio del

7 "The creation of new international regimes may be facilitated by the mutual confidence created by old ones. Regimes rarely emerge from chaos; on the contrary, they are built on one another".

8 Como se comenta en las conclusiones, lo más probable es que el futuro régimen internacional de CSS proponga una definición integradora de evaluación del desarrollo que intente compatibilizar el paradigma de gestión basada en resultados (y políticas basadas en evidencias) del CAD y el de gestión basada en aprendizajes (y políticas atentas al contexto político, institucional y de desarrollo) de la CSS, que, de hecho, están sintetizados por el Grupo de Evaluación de Naciones Unidas (DOMÍNGUEZ, 2018). 
régimen internacional afecta a las normas y principios, como el intento fallido que protagonizaron los países del G77 en la década de 1970 y ahora, ya bajo el predominio económico e ideacional de China, los grandes proveedores de CSS aunque esta vez con un éxito prácticamente asegurado.

El predominio ideacional actual de China se refleja en su propia teoría dominante de relaciones internacionales, el realismo moral (XUETONG, 2013, 2014, 2016), que, como rama del realismo, integra en una síntesis superadora elementos del institucionalismo neoliberal (la importancia de las normas asociada a la construcción de regímenes) y de la teoría crítica neogramsciana (la cuestión de la hegemonía). Las otras teorías chinas de relaciones internacionales, como el Tianxia y el relacionismo dialéctico constructivista (YAQING, 2012, 2014), son importantes para la retórica de la CSS, pero no dejan de resultar elementos fuertemente ideológicos (LI, 2016; BERNAL-MEZA, 2016) embellecedores del interruptor que hará funcionar el nuevo orden internacional. Ese nuevo orden se configurará a partir de los intereses nacionales y normas establecidas por China en su juego de poder de suma cero - en una competición que sigue siendo descrita como pacífica - con los EEUU (XUETONG, 2013, 2014, 2016 y 2018), y en las complejas relaciones de cooperación del gigante asiático con los otros BRICS (SINGH, 2016; MINGH, 2014; MOURON, URDINEZ, SCHENONI, 2016; FRENKEL, 2017; KOVRIG, 2017).

El apasionante debate académico actual en el campo de la teoría china de las relaciones internacionales entre Yaqing (con su epistemología constructivista) y Xuetong (con su epistemología racionalista) está mediado por la presión del test de una realidad sujeta a la ley de aceleración histórica y a la incertidumbre asociada a la elevada volatilidad geopolítica (BURROWS, BOHL, MOYER, 2017). El primer autor utiliza argumentos culturales (la dialéctica complementaria del zhongyong y su apuesta por el justo medio y las soluciones armónicas, pragmáticas y flexibles) para afirmar, a partir de un análisis muy centrado en los discursos, la continuidad de la estrategia de bajo perfil de China (YAQING, 2014). El problema de este planteamiento constructivista es que difícilmente se compadece con la veloz sucesión de los acontecimientos: el tránsito desde la política del pivote Asia-Pacífico de EEUU (en alianza con Japón) - para contener un ascenso de China que Washington consideró amenazaba a su hegemonía - a la autoexclusión de EEUU del Asian Infrastructure Investment Bank (AIBB, por sus siglas en inglés), lo que revela el fracaso de esa política de contención (XUETONG, 2016; WONG et al., 2007). Es indiscutible que China, como segunda economía mundial, está 
abocada a competir por la hegemonía con EEUU. A esa creciente e inocultable bipolarización, que deja obsoleta la estrategia conservadora del bajo perfil (de dominante económica), responde justamente la nueva estrategia de luchar por el éxito del premier Xi Jinping, con su nuevo liderazgo proactivo basado en la multiplicación de los diálogos políticos estratégicos (XUETONG, 2014 y 2016).

El juego de suma cero por el poder entre China y EEUU se explicitó con la idea del China Dream (el rejuvenecimiento nacional de China basado en acortar la brecha de poder integral con EEUU) expresada por Xi Jinping en 2013 a su llegada a la presidencia de la República Popular (SANTILLÁN, 2017) con Dos Objetivos Centenarios: duplicar el PIB per cápita chino de 2010 para 2020, centenario de la creación del PCC; y lograr una sociedad modestamente acomodada para hacer de China un gran país socialista moderno, de cara al centenario de la creación de la RPC en 2049 (TERRILL et al., 2016; XINHUA, 2017). Con esta idea, se busca evitar dos trampas: la trampa de renta media por medio de la innovación para convertir a China en un país desarrollado; y la trampa de Tucídides (aquella por la cual una potencia en ascenso causa temor en la potencia establecida, lo que conduce inevitablemente a un conflicto) por medio de la cooperación internacional (TERRILL et al., 2016). Por tanto, el juego de suma cero no elimina la cooperación económica y militar en un sistema internacional de actores, configuración (estructura) y normas que se sigue considerando anárquico (en el sentido de que no existe una autoridad central que lo regule): si las normas internacionales y la potencia militar son los dos medios fundamentales para mantener un orden internacional sostenible, China, como el principal entre los Estados ascendentes ${ }^{9}$, necesita afirmar su credibilidad estratégica internacional (que comprende los elementos de autoridad moral y consentimiento) generando alianzas por medio del diálogo político (XUETONG, 2016).

Dicho diálogo, además de cooperación para el desarrollo pacífico (que es la ideología de la iniciativa del Cinturón Económico de la Ruta de la Seda y la Ruta Marítima de la Seda del Siglo XXI), incluye también la cooperación en temas de seguridad y defensa con aquellos países vecinos incapaces de sobrevivir autónomamente a base de sus limitadas capacidades militares. Tales países de la llamada diplomacia periférica de China, junto con otros aliados extra-regionales - que empiezan a sentir las contradicciones de su alianza con EEUU (GUERRERO,

9 Xuetong $(2016$, p. 17, 24) ofrece dos definiciones de Estado ascendente: "a state whose comprehensive strength expands so dramatically that it narrows the strength gap with the dominant state and seizes some power from that dominant state"; "countries with fast-growing national strength which define as their strategic interests obtaining international leadership and creating a new international order”. 
2017; POGGETTI, 2017) -, aceptarán voluntariamente la autoridad internacional del nuevo líder en la medida en que éste proporcione credibilidad estratégica en el proceso de redistribución del poder internacional, esto es, provea de beneficios económicos y protección o seguridad en el orden alternativo como autoridad moral mejor acogida, porque realmente practica lo que predica y lo que predica es suficientemente atractivo en términos relativos (XUETONG, 2013, 2014).

Para el realismo moral, la autoridad internacional de un Estado líder se establece sobre la base de su alta credibilidad estratégica más que sobre su poder (XUETONG, 2016) y China, con la reiteración de sus compromisos a favor del multilateralismo, la globalización, el libre comercio, el acuerdo climático y la CSS empieza a revelarse a los europeos como un líder reformista (MAGALHÃES, 2018) más atractivo que los EEUU de Donald Trump, cada vez más cerca de la definición de Estado tiránico existente en el pensamiento chino (KATZ, 2017), en el que la palabra hegemonía tiene connotaciones negativas: un poder dominante sin crédito estratégico en cuanto a adherirse a la normas inter-estatales, basado en un liderazgo agresivo de carácter militar y en la conquista de otros territorios (XUETONG, 2016; XUETONG, 2018).

Dado que los Estados ascendentes intentan incautarse de más poder internacional, mientras el Estado dominante rechaza compartir su poder de liderazgo con los Estados emergentes, incluso aunque su potencia relativa decline, se explica así que el Estado dominante a menudo enfatice la importancia de mantener el orden internacional existente, mientras los Estados ascendentes defiendan el establecimiento de un nuevo orden (XUETONG, 2016). Y para aumentar su poder integral a nivel internacional - que es producto de la suma de las capacidades económicas, militares y culturales, multiplicadas (de ahí su mayor importancia) por el poder político (XUETONG, 2013, 2016) -, un Estado ascendente necesita reforzarse mediante aliados si no puede recurrir a anexiones territoriales (XUETONG, 2014). Como, a diferencia de EEUU, Reino Unido u Holanda - los poderes hegemónicos previos - China no fomentará el secesionismo a fin de evitar el peligro de su propia desintegración territorial (KARATASLI, KUMRAL, 2017), e intentará buscar aliados activamente o esperará dejarse querer. Tal actitud se irá intensificando a medida que el liderazgo agresivo de Trump (de dominante militar, como indica su solicitud al Congreso del aumento del gasto en defensa "para volver a ganar guerras") acabe por debilitar, como de hecho ya lo está haciendo, las tradicionales alianzas del poder hegemónico de los EEUU (XUETONG, 2016, 2018; WONG et al., 2017; GUERRERO, 2017). 
La conclusión de tales planteamientos es que cuando un Estado ascendente tiene un amplio grupo de aliados, podrá movilizar el apoyo internacional para su proyecto de nuevo orden internacional (XUETONG, 2016). Esta es precisamente la situación en la que nos encontramos desde 2015, con la creación, por China, del AIIB, con sus actuales 63 miembros plenos ( 42 regionales y 21 extra-regionales) y 21 prospectivos (6 y 15 respectivamente) (AIIB, 2018). Y también con el anuncio, por Xi Jinping, dos años antes, en el marco de su política de renacimiento de China, de la ahora conocida en inglés como The Belt and Road Initiative (BRI) (TERRILL et al., 2016; DIRMOSER, 2017). La BRI agrupa a 65 países, con posibilidad de ampliación hasta otros 48 (CHIN, HE, 2016; WONG et al., 2017) y ha sido calificada como el Plan Marshall de China (TIEZZI, 2014). La idea, no obstante, proviene del reciclado de la Iniciativa Global de Infraestructura que presentaron Justin Yifu Lin (tras dejar el cargo de economista jefe y vicepresidente del Banco Mundial entre 2008 y 2012) y Yan Wang en 2013 al High Level Panel sobre la Agenda de Desarrollo post-2015 de Naciones Unidas con el título de Más allá del Plan Marshall (LIN, WANG, 2017). La BRI mantiene esa característica de superar el Plan Marshall, por dos motivos: por el valor de su cartera actual de proyectos que asciende a la astronómica cifra de $926.000 \$$ millones, frente a los $142.000 \$$ millones que tendría el valor actualizado del Plan Marshall; y porque, a diferencia del Plan Marshall y su orientación anticomunista, el Plan Xi Jinping (6,5 veces el Plan Marshall) está abierto a todos los países del mundo (DOMíNGUEZ, 2017b). Esta iniciativa y sus instituciones de financiación apuntan claramente a la construcción de un régimen internacional de CSS liderado por China, que cuenta ya con un amplio aparato de legitimación y gestión del conocimiento ${ }^{10} \mathrm{y}$ con una doctrina sobre derechos humanos (ZHISHANG, 2011; ZHENGQUING, ZHIYONG, XIAOFEI, 2017) recién multilateralizada en el Primer Foro Sur-Sur sobre Derechos Humanos celebrado en Beijing en 2017, que, respetando la integralidad de la Declaración Universal de 1948, prioriza el derecho a la subsistencia y el derecho al desarrollo (DOMÍNGUEZ, 2017b).

10 El CAITEC (Chinese Academy of International Trade and Economic Cooperation, creado en 1983), con sus 140 investigadores, así como otras instituciones clave como la Peking University (1912), la China Foreign Affairs University (1955) y el China Institute of International Studies (1956), son los principales tanques de pensamiento. Además, y como parte del esfuerzo para liderar la Agenda de Desarrollo 2030, en 2015 se crearon el International Development Knowledge Center y el Institute of South-South Cooperation and Development (este último dirigido por Justin Yifu Lin), ambos con sede en Beijing. 


\section{Evidencia empírica: mirando atrás para tomar impulso}

Para verificar si existe la voluntad política y las acciones concretas tendentes a crear un régimen internacional de CSS, esto es, un cambio de régimen internacional (de sus principios y normas), es necesario echar la vista atrás a fin de comparar los procesos actuales con la experiencia histórica. Al hacerlo, se constata que la evaluación fue el pilar institucional clave del Plan Marshall, que luego fue tomado como referencia por los países de la periferia para reclamar un régimen de cooperación equitativo asentado en Naciones Unidas. Sin embargo, EEUU (y sus aliados europeos) dieron preferencia a la institucionalidad financiera, partiendo del US Exim Bank, con el Banco Mundial (IBRD, en sus siglas en inglés, de 1944) y sus diversas agencias (International Finance Corporation en 1956 e IDA en 1960), el Banco Europeo de Inversiones (1958) y el Banco Interamericano de Desarrollo (1959) (SOGGE, 2009; DOMÍNGUEZ, 2017a). De ahí que la definición de ayuda al desarrollo en la década de 1960, tras la creación del CAD (1961), estuviera dominada por el debate sobre los términos y condiciones de los créditos concesionales a los países en desarrollo (DOMÍNGUEZ, TEZANOS, 2012; SCOTT, 2015; DOMÍNGUEZ, 2017a).

En la década de 1960, los países en desarrollo que integraron el club del G77 (y su club complementario del Movimiento de Países No Alineados, NAM, por sus siglas en inglés) hicieron esfuerzos políticos de intensidad creciente para levantar, por medio de la acción colectiva, un régimen internacional de CSS alternativo al régimen internacional de la ayuda del CAD y sus tres pilares. Tal proyecto político de construcción de una coalición internacional, que desafiaba la hegemonía de EEUU - en donde Hans Morgenthau (1968) identificó a China como la nación más poderosa de Asia continental y potencialmente la nación más poderosa del mundo ${ }^{11}$ - fue el resultado de comprobar que la creación de un régimen internacional de cooperación basado en los principios de la Carta de Naciones Unidas ("un mecanismo internacional para promover el progreso económico y social de todos los pueblos... dentro de un concepto más amplio de la libertad") era una quimera.

11 Retrospectivamente, la visión de Morgenthau sobre China resultó abrumadoramente certera: “China is, even in its present underdeveloped state, the dominant Power in Asia. It is this by virtue of the quality and quantity of its population, its geographic position, its civilization, its past power remembered, and its future power anticipated" (MORGENTHAU, 1968, p. 30). 
China e India son los dos países que, en la actualidad, están empujando más fuerte a favor de un régimen internacional de CSS a resultas de que defendieron históricamente una política económica de desestructuración de su situación colonial (India) o semicolonial (China) y una política exterior autónoma de no alineamiento (MUKHERHEE, 2012; CHAKRABARTI, 2017). En 1954, China e India declararon conjuntamente cinco principios para regir sus relaciones (coexistencia pacífica, respeto mutuo de la soberanía y la integridad territorial, no injerencia en los asuntos internos, no agresión, igualdad y privilegios recíprocos). Dichos principios, conocidos como Panchsheel en India, pero debidos al genio chino de Zhou Enlai, que fue quien los formuló en 1953 (BOYOU, 1993; MONCADA, 2011; DASGUPTA, 2016), se integraron en el llamado espíritu de Bandung un año después. La Conferencia Afro-Asiática dio origen al nacimiento del Tercer Mundo, y también al alumbramiento de la CSS como cooperación económica en forma de acción colectiva concretada en la demanda de un Fondo Especial de Naciones Unidas de financiación a fondo perdido - y mediante la transferencia neta de recursos- para la industrialización de las materias primas y la promoción del comercio entre países en desarrollo (ASSIE-LUMUMBA, 2015; PEREIRA, MEDEIROS, 2015). Semejante proyecto y sus objetivos no eran del interés de los EEUU y sus aliados europeos, que se encontraban inmersos en la creación del régimen internacional de la ayuda, entendida como crédito concesional para facilitar la inversión extranjera en los países en desarrollo (BARAN, 1962; MELO, YOST, 1970a y 1970b, DOMÍNGUEZ, 2017a) y para mantener, por medio del "programa de desarrollo" superador del "viejo imperialismo" (tal y como expuso el presidente Truman en el Cuarto Punto de su Discurso de 1949), la dependencia neocolonial (BARAN, 1962; NKRUMAH, 1966; BYRES, 1972; SOGGE, 2009).

El espíritu de Bandung inspiró la creación del NAM durante la Conferencia de Belgrado (1961), la primera en la que se reclamó la celebración de una conferencia internacional de todos los países para discutir un acuerdo sobre las medidas más efectivas que asegurasen la realización de su desarrollo económico y social, mediante una cooperación efectiva en el campo económico y comercial (IFA, 2011). Unas semanas después de Belgrado, la Asamblea General de Naciones Unidas aprobó la Década del Desarrollo y la Resolución 1716 (XVI) sobre "el comercio internacional como principal instrumento para el desarrollo económico”, en la que se instaba a hacer una consulta sobre la conveniencia de celebrar una conferencia internacional monográfica sobre ese tema (cfr. DOMÍNGUEZ, 2016a, p. 62). En 1962, pero sin el auspicio de Naciones Unidas, tuvo lugar ese 
evento, bajo la denominación de Conferencia sobre los Problemas del Desarrollo Económico de El Cairo, que agrupó por primera vez a 36 países de África, Asia y América Latina. La Declaración de los Países de Menor Desarrollo (1962), con la que concluyó el encuentro de El Cairo, instó a los participantes a coordinarse para preparar la "Conferencia Económica Mundial de las Naciones Unidas" (cfr. DOMÍNGUEZ, 2016a, p. 63), que se concretó después de la I Conferencia de Naciones Unidas sobre Comercio y Desarrollo (UNCTAD, por sus siglas en inglés), celebrada en Ginebra en 1964. Al término de la I UNCTAD, el Grupo de los 77 (G77), integrado por los países de América Latina (Grupo C), y el resto del bloque Afro-Asiático (Grupo A), hizo una Declaración Conjunta a favor de la creación de un "nuevo orden económico mundial justo" y la transferencia neta de recursos de los países desarrollados equivalente al $1 \%$ de su PNB, pero obtuvo la misma respuesta frustrante que la dada a las peticiones de Bandung y El Cairo: los donantes del CAD se limitaron a perfilar la definición de AOD en términos de crédito concesional bendecidos por la comisión de expertos "independientes", auspiciada por el Banco Mundial, responsables del Informe Pearson de 1969 (cfr. DOMÍNGUEZ, 2016a, p. 64).

A la vista de estos magros resultados, la III Conferencia del NAM (Lusaka, 1970) decidió fomentar la cooperación mutua entre los países en desarrollo, potenciando las complementariedades de recursos y la integración a nivel regional e interregional, para lo cual aprobó un genérico Programa de Acción a fin de favorecer el comercio de bienes y servicios entre los 53 países no alineados de entonces, y también la cooperación para el desarrollo de los sectores productivos, las infraestructuras y la ciencia y tecnología (IFA, 2011). Luego, durante la III UNCTAD (Santiago de Chile, 1972), se propuso la redacción de una Carta de los Derechos y Deberes Económicos de los Estados. Dicha Carta que sería aprobada dos años después en la Asamblea General de Naciones Unidas, constituyó el momento culminante de la reivindicación del Nuevo Orden Económico Internacional (NOEI) y su concepto, originalmente chino (WHEELER SNOW, 1977), de la autodeterminación colectiva para la construcción de una arquitectura institucional (un verdadero régimen internacional de cooperación alternativo al del CAD) conforme a las preferencias de un Sur Global cada vez más asertivo y autónomo (AMIN, 2016).

En ese contexto es en el que se empezó a hablar de la creación de un "Banco de Inversión del Tercer Mundo" o sencillamente "Banco del Tercer Mundo", denominado enseguida "Banco de los Países en Desarrollo" en la declaración 
final de la Conferencia del G77 sobre Cooperación Económica de los Países en Desarrollo (México, 1976), y después "Banco del Sur" por la Comisión del Sur en su informe de 1990 (cfr. DOMÍNGUEZ, 2016b, p. 70). En paralelo, el Grupo Especial de Trabajo del Foro del Tercer Mundo (como think tank del G77) planteó en 1975 "el establecimiento de un Centro para el Desarrollo del Tercer Mundo", a modo de "contraparte tercermundista de la OECD" (ANÓNIMO, 1975), siendo que una de las resoluciones de la IV UNCTAD (Nairobi, 1976) fue establecer un Comité abierto de Cooperación Económica entre los Países en Desarrollo, cuya función sería considerar "medidas para proporcionar, cuando así se le solicite, apoyo y asistencia a Países en Desarrollo en el fortalecimiento y ampliación de la cooperación mutua a nivel subregional, regional e interregional" (UNITED NATIONS, 1977, p. 40, versión libre del autor) ${ }^{12}$.

Ante la decepción provocada por las prácticas de ayuda atada, reversa y condicionada y por los incumplimientos sistemáticos de los compromisos voluntariamente adquiridos por los países del CAD en la financiación suplementaria y la cooperación (a través del sistema de preferencias generalizadas y transferencias de tecnología), los países del G77 decidieron reforzar la cooperación económica entre ellos (DOMÍNGUEZ, 2016a). Esa genuina y autónoma CSS constituyó el programa de máximos de la Conferencia de Cooperación Económica de los Países en Desarrollo (México, 1976). La historia de cómo ese intento fue arrumbado por las acciones disolventes y divisivas de los países desarrollados (incluyendo el sucedáneo de CSS reducida a cooperación técnica entre países en desarrollo del PNUD glorificada en Buenos Aires en 1978, y la disolución en la década de 1990 del Comité de Cooperación Económica entre los Países en Desarrollo de la UNCTAD) ya ha sido contada en otra parte (DOMÍNGUEZ, 2016a). Hoy, en cambio, la creación de un régimen internacional alternativo parece que esta vez va bien encarrilada, y desde el Sur Global se reclama un Bandung II, a modo de evento fundacional para coordinar a los BRICS, el G77 y el NAM (RIS, 2016a), mediante una Comisión del Sur que "aborde la cuestión de qué puede hacer el

12 "measures to provide, as and when requested, support and assistance to developing countries in strengthening and enlarging their mutual co-operation at the subregional, regional and interregional levels”. Después, en 1982, Gonzalo Martner, economista chileno director de la Oficina de Planificación, Programación y Evaluación de Naciones Unidas, seguiría abogando por "una especie de «Organización de Cooperación entre Países en Desarrollo»" como contraparte de la OCDE y el CAME (Consejo de Ayuda Mutua Económica); y en 1990 la Comisión del Sur, creada en 1987, sugirió el establecimiento de un Secretariado del Sur, que quedó después reducido al modesto Centro del Sur y se convirtió finalmente en organización internacional del G77 en 1995 (cfr. DOMÍNGUEZ, 2016b, p. 70). 
Sur por sí mismo a través de la CSS y cómo ello puede influir en la configuración del orden mundial en el futuro mediante la acción colectiva" (GOSOVIC, 2016, p. 740, versión libre del autor) ${ }^{13}$.

Pero todo este proceso no se puede entender al margen del irredentismo que tanto China como India han mantenido en su política exterior por décadas. Un irredentismo que se basa en restaurar, tras las humillaciones del período colonial y del imperialismo europeo y japonés, la aportación civilizatoria de ambos países a un orden mundial verdaderamente universal, acorde con esa herencia cultural y peso económico de Asia-Pacífico - el nuevo epicentro de la economía mundial, tal y como previó en 1988 el otro gran genio chino, Den Xiaping ${ }^{14}$-, y que debe servir para maximizar su soberanía territorial y estatus internacional respectivos (BOYOU, 1993; MONCADA, 2011; LIN, 2013; CALLAHAN, 2016; HARRIS, ARIAS, 2016; CHAKRABARTI, 2017; XIAOYU, 2017; MAGALHÃES, 2018; XUETONG, 2018) a partir de los Cinco Principios de Coexistencia Pacífica entre las dos naciones, como ya vio Deng Xiaping en 1988 cuando señaló que los principios era muy explícitos, útiles y claros y que deberían ser usados como guía normativa para las relaciones internacionales (XIAOPING, 1994).

China, que había tenido una activa participación en la agenda para el establecimiento del NOEI (ROCH, 1980), siguió promoviendo - en medio del ataque del G7 y sus organismos multilaterales financieros a la unidad del G77 - la CSS como elemento cohesionador para mantener viva la llama de la agenda tercermundista (YAHUDA, 1970; CONNELLY, 1991). Tal y como rezan las conclusiones de la I Conferencia Sur-Sur de Beijing (1983), la CSS debía dar prioridad a la cooperación financiera, para lo cual se buscó hacer operativo el "Banco de los Países en Desarrollo", propuesto por el G77 en la Reunión Ministerial de Arusha previa a la V UNCTAD (Manila, 1979) (MEDINA, 1983; UNITED NATIONS, 1981). En 1983, también se celebró en Nueva Delhi la VII Conferencia del NAM (99 países), en la que India se proyectó como líder del Sur Global. Allí reclamó la democratización del sistema internacional - que era la esencia de la

13 "to address the question of what the South can do for itself through SSC and how it can influence the shaping of the world order and the future by acting collectively".

14 En sus conversaciones con el primer ministro de India, Rajiv Gandhi, en diciembre de 1988, Deng manifestó que el próximo siglo sería el siglo de Asia-Pacífico, pero no como se preveía entonces, centrado en el eje EEUU-Japón-Dragones Asiáticos-Australia-Nueva Zelanda. "A true Asia-Pacific or Asian century will not emerge unless China, India and some of their neighbouring countries have developed... China pursues a policy of reform and opening to the outside world, striving to become developed within a 50 to 70 year period. If China and India become developed, it can then be said that we have made contributions to mankind" (XIAOPING, 1994, p. 267-268). 
agenda del NOEI -, a fin de reforzar la posición de los países en desarrollo en las negociaciones con los países desarrollados sobre bases de igualdad y mutuo beneficio (IFA, 2011; CHAKRABARTI, 2017).

Pero en ese momento de principios de la década de 1980, ni China ni India tenían la potencia económica suficiente para llevar a cabo la tarea de liderar la construcción de un régimen internacional de CSS, ni siquiera, pese al mejor entendimiento entre ambos países, tras la restauración de sus relaciones diplomáticas en 1976 (Cuadro 1).

\section{Cuadro 1. Evolución del peso económico relativo de China} y otros países emergentes en paridad de poder adquisitivo

\begin{tabular}{|l|c|c|}
\hline & \% PIB mundial en 1980 & \% PIB mundial en 2017 \\
\hline Países en desarrollo & 36,29 & 58,67 \\
- China & $(2,32)$ & $(18,11)$ \\
- India & $(2,93)$ & $(7,59)$ \\
- BRICS & & $(31,89)$ \\
\hline Países desarrollados & 63,71 & 41,33 \\
- G7 & $(51,15)$ & $(30,60)$ \\
- UE (pre Brexit) & $(24,61)$ & $(16,46)$ \\
- EEUU & & $(15,55)$ \\
\hline
\end{tabular}

Fuente: elaboración propia a partir de Economy Watch $(1980,2017)$.

En 1980, China e India representaban una proporción muy pequeña del PIB mundial, que seguía dominado por los países avanzados y su núcleo duro del G7. Pero en 2017, los BRICS superan ligeramente la proporción del G7, China está por encima de la UE pre-Brexit y de EEUU, y los países emergentes y en desarrollo desbordan a los países avanzados. Por tanto, las condiciones materiales objetivas de acumulación de capital (KELLOG, 2015) y los demás fundamentos de poder económico de China y los países del Sur (RIS, 2016b) apuntan a que la voluntad política manifiesta y las acciones concretas de China como líder del G77, arropado por los BRICS, pueden esta vez levantar un régimen de CSS alternativo al del CAD.

A partir de 1995, China reformó su cooperación económica, empaquetando las donaciones a fondo perdido y los préstamos sin interés, junto con créditos concesionales, inversión extranjera directa (de su empresas estatales) y acuerdos comerciales, de manera que llegó muy bien preparada para la nueva carrera por África que se iba a desatar en el segundo lustro de la década de 1990. La visita de Jiang Zemin a la región, en 1996, (donde lanzó la idea del Foro de Cooperación 
África-China, FOCAC por sus siglas en inglés) fue el detonante de la estrategia Going Out, incorporada luego al X Plan Quinquenal 2001-2005, y que quedó como elemento permanente la acción exterior, junto con el desarrollo pacífico, de la mano del ingreso de China en la OMC y de los diálogos políticos estratégicos con la Asociación de Naciones del Sudeste Asiático (ASEAN, por sus siglas en inglés, desde 1996, y con la condición de estratégicos desde 2003), África (desde 2000, y con la condición de estratégicos desde 2005) y América Latina (estratégico desde su inicio, en 2015), y, por supuesto, la BRI, presentada oficialmente en 2015 para el XIII Plan Quinquenal 2016-2020 (XIAOYU, 2017; ASEAN, 2017; HARRIS, ARIAS, 2016; ASSIE-LUMUMBA, 2015; SINGH, 2017a).

Resulta simbólico que fuera La Habana, en 2000, la sede de la I Cumbre del Sur del G77 y China, y no menos simbólica fue la elección de Santa Cruz en Bolivia como sede de la Cumbre del G77 y China para celebrar, en 2014, el 50 aniversario de la creación del grupo, actualmente integrado por 133 Estados más China. La Declaración de Santa Cruz afirmó el compromiso colectivo del G77 + China de "asumir un papel rector para dar forma a la agenda internacional para el desarrollo después de 2015” (cfr. DOMÍNGUEZ, 2016a, p. 70). En congruencia con ello, el año de inicio de la Agenda de Desarrollo Sostenible 2030 (2016), China se convirtió en la influencia principal en el mundo de la arquitectura internacional del desarrollo (CAREY, XIAOYUN, 2016).

La BRI, anunciada por Xi Jinping, en 2013, en el marco del diálogo político estratégico con el ASEAN, fue oficializada en 2015. Con las instituciones financieras ya en operación para apoyarla sobre la doble premisa de evitar condicionalidades del tipo FMI y eludir el dominio del dólar en la financiación global, China ha dado el gran salto adelante internacional para desplazar el centro del poder del Atlántico al Pacífico y configurar un nuevo orden mundial sobre la base de su potencia económica, militar y cultural y su credibilidad estratégica objetivamente verificada por la multiplicación de países aliados (XUETONG, 2016; CALLAHAN, 2016; MAGALHÃES, 2018). En efecto, China cuenta ya con el New Development Bank (dotado con 50.000\$ millones, de los cuales China aporta 10.000\$ millones, que esperan duplicarse) y el AIIB (con 100.000 \$ millones), como bancos de carácter multilateral; y con el Fondo de la Ruta de la Seda, de 2014 (con 40.00\$ millones), que se alimenta de la financiación de los dos principales bancos de desarrollo internacional de China (el China Exim Bank y el China Development Bank, que, en 2016, mantuvieron activos externos por valor de 500.000\$ millones). A ello se unen los cuatro bancos de desarrollo nacionales de China, de carácter 
bilateral, con carteras internacionales gigantes (en 2013, 373.000\$ millones), con lo que la banca china de desarrollo superaría ampliamente a la banca de desarrollo occidental (el Grupo Banco Mundial más los cuatro bancos regionales de desarrollo sumaron, en 2016, una cartera de créditos de los 700.000\$ millones). A estos dos grupos multilaterales y nacionales hay que añadir, finalmente, el Fondo de Reservas de Contingencia de los BRICS (con 100.000\$ millones, de los cuales China aporta $41.000 \$$ millones), el proyectado Shanghai Cooperation Organization Development Bank, y, en América Latina, el Fondo de Inversiones China-CELAC (20.000\$ millones) y el Fondo de Cooperación de Industrial China-América Latina (10.000\$ millones) (SEN, 2016; KAMAL, GALLAGHER, 2016; MAGALHÃES, 2018).

Contando con el respaldo en su retaguardia de la comunidad de seguridad de la Organización de Cooperación de Shanghai - que incluye desde su creación, en 1996, a Rusia y, desde 2016, a India ${ }^{15}$-, China está en condiciones de situarse, a partir de la BRI, como el nuevo líder de un régimen internacional de CSS (LIM, 2015; DOMÍNGUEZ, 2016a; WONG et al., 2017). Importa señalar que esta iniciativa abarca también (por la Ruta Marítima) a América Latina, con la plataforma de la isla de Cuba a modo de base naval y los proyectos de comunicación del Gran Canal de Nicaragua, el ferrocarril bioceánico Brasil-Perú y el túnel Argentina-Chile, como megaproyectos principales. De ahí que en el Belt and Road Forum for International Cooperation, de mayo de 2017 - al que asistieron representantes de 70 países, de entre ellos 29 Jefes de Estado y de Gobierno -, se produjo la comparecencia de Macri y Bachelet. En todo caso, lo más impactante fue la representación multilateral del máximo nivel, con el Secretario General de Naciones Unidas, el Presidente del Banco Mundial, la Directora Gerente del FMI y el Presidente del BID.

Frente al nacionalismo económico y revisionismo climático de Trump, que está acelerando a marchas forzadas la pérdida de credibilidad estratégica y de autoridad que EEUU fue acumulando desde la invasión de Irak (2003) y con su responsabilidad máxima en la crisis financiera de 2008 (DOMÍNGUEZ, 2106a; XUETONG, 2013 y 2016; GUERRERO, 2017), hay tres elementos complementarios a la BRI que permiten vislumbrar la trayectoria imparable de China hacia el predominio mundial y su consiguiente papel de rule maker de la gobernanza global (CALLAHAN, 2016; LI, 2016; MAGALHÃES, 2018). Tales elementos son:

15 Aunque los medios occidentales tratan de magnificar las diferencias entre India y China, acentuadas ahora por el corredor China-Pakistán de la BRI (FUES, 2017; KOVRIG, 2017), el análisis histórico de esta relación obstinada indica que ambos países están condenados a entenderse (SINGH, 2017b). 
i) la condición que ha alcanzado China en 2015 como exportador neto de Inversión Extranjera Directa (IED), con una presencia masiva en la UE en los últimos años (35.000€ millones solo en 2016, el triple del monto de la IED china en América Latina y el Caribe), y la incorporación al accionariado del Banco Europeo de Reconstrucción y Desarrollo (GUERRERO, 2017; AVENDANO, MELGUIZO, MINER, 2017); ii) la integración del yuan/renminbi en la cesta de divisas de sistema de Derechos Especiales de Giro del FMI en octubre de 2016 (donde China es el tercer accionista casi igualando la cuota de Japón), y como corresponde a la condición de China de primer exportador y segundo importador a nivel mundial, que mantiene acuerdos SWAP firmados con más de 30 países (ARNER, SOARES, 2016; MAGALHÃES, 2018); y iii) la previsible firma del Regional Comprehensive Economic Partnership Agreement (RCEP, que agrupa a los 10 países del ASEAN, más China, India, Japón, Corea del Sur, Australia y Nueva Zelanda) para finales de 2018, ante la retirada de EEUU del Acuerdo Transpacífico de Cooperación Económica (TPP por sus siglas en inglés), lo que da a China la centralidad en el Pacífico (DOMÍNGUEZ, 2016a; ARNER, SOARES, 2016; SESHADRI, 2017; WONG et al., 2017). El RCEP incluso abre la posibilidad de un acuerdo más amplio en el seno del Foro de Cooperación Económica Asia-Pacífico (APEC por sus siglas en inglés), en el que, además de Rusia y Canadá, también están presentes tres de los países de la Alianza del Pacífico (México, Perú y Chile), que se han quedado con la puerta en las narices tras la retirada de EEUU del TPP (reiterada por Trump en la última cumbre de la APEC en noviembre de 2017), acuerdo este del RPEC que analistas contemplan como una iniciativa de China sinérgica con la BRI (SOLÍS, 2017; SESHADRI, 2017) y que la firma de los 11 socios del TPP sin EEUU (marzo de 2018) no cambiará sustancialmente (GILLESPIE, 2018).

El nuevo régimen internacional de CSS en construcción cuenta ya con una doctrina generada en el NeST, la red de think tanks del Sur que surgió en la Conferencia de Proveedores del Sur (Delhi, 2013) y con fuerte peso intelectual de India, que está apostando fuerte por una narrativa propia de CSS. India propone desbordar al CAD bajo la fórmula del One-World-ism, según la cual, la CSS, mientras promueve la cooperación ampliada entre los países del Sur, también engloba la cooperación Norte-Sur en su visión holística (FIDC/RIS/NeST, 2016). En el mismo documento, generado para la Conferencia Afro-Asiática de 2015 (bajo el lema "Fortaleciendo la CSS para la paz mundial y la prosperidad"), el presidente del RIS, Shyam Saran, ex Secretario de Exteriores de India, hizo dos afirmaciones contundentes sobre la manera alternativa de aproximarse a las cuestiones de la 
cooperación para el desarrollo basada en normas diferentes de las de la OCDE, y sobre la creación de un nuevo consenso internacional sobre cooperación para el desarrollo ${ }^{16}$.

Ni que decir tiene que el One-World-ism es congruente con la doctrina globalista china del Tianxia (literalmente, lo que está bajo el cielo), que promueve una cooperación ganar-ganar dentro de una visión armónica (YAQING, 2012) y sinocéntrica de las relaciones internacionales, la comunidad de intereses, destino y responsabilidades compartidas, con que se anunció la BRI (CALLAHAN, 2016), una iniciativa que, enraizada en el pensamiento fuertemente desarrollista de Confucio ${ }^{17}$, se considera como un modelo superior de globalización. Este modelo, que el presidente Xi Jinping describió con gran entusiasmo en su apoteosis de Davos de enero de $2017^{18}$, es una proyección del milagro del desarrollo de China, basado en los principios de la economía política socialista con características chinas (ENFU, XIAOQUIN, 2017), que, desde la teoría del realismo moral, se reconoce tienen la función de legitimación fundamental para la credibilidad estratégica internacional del gigante asiático (XUETONG, 2018), de ahí la recomendación de "practicar la ideología de la rectitud, la justicia, la civilidad, tanto en casa como fuera, por el bien de sus propios intereses estratégicos así como para los del mundo" (XUETONG, 2016, p. 26, versión libre del autor) ${ }^{19}$.

Al margen de estos elementos ideacionales, importa señalar que, por primera vez desde Bretton Woods, una institución multilateral clave como el AIIB, no cuenta con la presencia de EEUU, pero sí con los países de la UE (y Reino Unido), además de Australia y Corea del Sur, y solo Japón (de momento y contra la presión de las grandes multinacionales del país favorables a la participación de su gobierno en la nueva entidad), ha permanecido junto a EEUU, lo que ha introducido

16 Saran es uno de los autores del documento de referencia sobre el nuevo no alineamiento de India en el que se dice que India debe permanecer fiel a su aspiración de crear una nueva universalidad alternativa (cfr. CHAKRABARTI, 2017).

17 Con valores como la diligencia y disciplina colectivas, orientación a resultados, capacidad por selección meritocrática, y austeridad del modo de vida, que son el trasunto (o más bien el precedente) de la ética protestante sistematizada por Max Weber (CORNEJO, 1997; LIN, 2013). Para una valoración reciente de estos aspectos y sus implicaciones políticas y económicas, véase BELL (2015) y POZNANSKI (2017).

18 Xi defendió la globalización como “un resultado natural del progreso científico y tecnológico” y como “un tendencia histórica” inescapable de consecuencias netamente positivas, que deben maximizarse con más innovación, arreglos institucionales de liberalización y apertura del comercio y la inversión (basados en juegos ganar-ganar que "digan no al proteccionismo"), y una gobernanza económica internacional "justa y equitativa” (cfr. DOMÍNGUEZ, 2016a, p. 59).

19 "to practice the ideology of fairness, justice, and civility, both at home and abroad, for the sake of its own strategic interests as well as those of the world". 
una división inédita dentro de la OCDE que hace parte del proceso de erosión hegemónica (WONG et al., 2017; GUERRERO, 2017). Con sus 63 miembros plenos y 21 prospectivos, el AIIB es la materialización institucional de las tres ideas fuerza encadenadas del realismo moral: que "la autoridad internacional de un Estado líder se establece sobre la base de su elevada credibilidad estratégica más que de su poder"; que "la alta credibilidad estratégica de un Estado ascendente contribuye a que establezca su nuevo orden internacional a través de la redistribución del poder internacional"; y que "cuando un Estado ascendente tiene un amplio grupo de aliados es capaz de movilizar el apoyo internacional para su proyecto de nuevo orden internacional y viceversa" (XUETONG, 2016, p. 22-23, versión libre del autor ${ }^{20}$. A resultas del hipercrecimiento de los últimos treinta años, China tiene una clase media pujante y ese enorme mercado interno se va a convertir muy pronto en el mayor del mundo, de manera que el acceso a dicho mercado será la baza del poder de negociación internacional de China, cuya posición "en la economía global se está comenzando a parecer a la de EEUU en el periodo de posguerra, cuando era la potencia económica predominante”, como señala el premio Nobel de Economía 2001 en un artículo para Project Syndicate (SPENCE, 2017). En este contexto, China avanzará hacia "un marco multilateral abierto y basado en reglas” y con ello "afirmará la influencia internacional del país”, gracias a que dicho marco contará con "un amplio apoyo de otros países de economías avanzadas y en desarrollo” (SPENCE, 2017).

El AIIB podría alcanzar en 2020 una capacidad de inversión de 250.000\$ millones, lo que supondría duplicar el actual tamaño del Banco Asiático de Desarrollo, liderado por Japón con el apoyo de EEUU (KAMAL, GALLAGHER, 2016). Esta desproporción abre el debate sobre la transición del poder internacional, en el que se pueden perfilar tres posturas. Para unos, China debe aspirar a ejercer la hegemonía y parece encaminada a ello gracias al liderazgo pro-activo de $\mathrm{Xi}$ Jinping que está favoreciendo las alianzas políticas y de seguridad estratégicas por medio del AIIB y la BRI (XUETONG, 2016; SINGH, 2017a; WONG et al., 2017). Para otros, China heredará en algún momento esa hegemonía de EEUU que cambiará a una división centro-periferia de dominante Sur (LI, 2016). Una tercera posición mantiene que el gigante asiático buscará una globalización de

20 "The high international strategic credibility of a rising state contributes to its establishment of a new international order through redistribution of international power... the high international strategic credibility of a rising state also has strong impact on the redistribution. When a rising state has a large group of allies it is able to mobilize international support for its blueprint for a new international order, and viceversa”. 
características chinas, de multilateralismo liderado por el Sur (LIN; WANG, 2017), y, por tanto, sin hegemonía (HENDERSON, APPLEBAUM, HO, 2013; CALLAHAN, 2016; PARK, 2016; AMIN, 2016), como recién manifestó Xi en el XIX Congreso del Partido Comunista y ahora trata de teorizar, matizando sobre la marcha, Yan Xuetong (2018) con su propuesta a favor de una fusión entre los valores del orden liberal y del pensamiento tradicional chino.

Esta última propuesta de Xuetong (2018) consiste en modernizar el principio tradicional del liderazgo basado en la autoridad humana (wang) y resulta fácilmente armonizable con la ideología oficial del XIX Congreso (con su mezcla de principios fundamentales del marxismo y esencia cultural tradicional autóctona), cuyo principal ideólogo es Wang Huning, internacionalista y experto en filosofía política, responsable de la teoría del sueño chino del rejuvenecimiento nacional, así como de las anteriores del desarrollo pacífico de Hu Jintao y de la triple representatividad de Jian Zeming (BORRÀS, 2018. El principio del wang es un estilo de liderazgo que predica con el ejemplo y produce logros demostrables (en ambos casos, dando consistencia a lo que se hace en casa y lo que se practica en política exterior), y su propósito es mejorar la reputación estratégica internacional. Para ello, el wang aplica los valores de la benevolencia (que enfatiza la empatía y el cuidado), hacer lo correcto (en términos de comportamiento para llegar a resultados justos) y atenerse a normas, de acuerdo a un ética universalista basada en la regla de oro para prevenir los conflictos. Dicha ética, enraizada en los Cinco Principios de la Coexistencia Pacífica (BOUYOU, 1993), puede ser compartida por las religiones globales y los organismos internacionales, siendo favorable, además, a los países pequeños y más débiles, que constituyen la mayoría en la Asamblea General de Naciones Unidas (XUETONG, 2018).

\section{Conclusiones: el futuro sí es lo que era}

El trabajo confirma las dos hipótesis predictivas. China está a punto de terminar el diseño de un nuevo régimen internacional de CSS, el cual va a liderar gracias al gran salto realizado por este país en términos de potencia y credibilidad estratégica internacionales, o, dicho de otro modo, gracias a su irresistible resurgimiento (frente a la imparable pérdida de peso económico y autoridad política de EEUU). Este nuevo régimen, que será alternativo al del CAD en sus estrategias de, políticas de cooperación para y concepción misma del desarrollo, necesitará afianzar sus tres pilares, siguiendo la tesis del isomorfismo institucional. 
En primer lugar, el pilar de la institucionalidad que le proporcionan en el plano financiero el Fondo de Contingencia de Reservas de los BRICS (para la provisión de crédito a corto plazo) y el New Development Bank y el AIIB (para la provisión de crédito a largo plazo): en todos los casos, no hay imposición de condicionalidades de política económica y reformas institucionales del Consenso y Post-Consenso de Washington, sino que se mete presión a EEUU para negociar cambios en la arquitectura financiera internacional y sus modalidades crediticias concesionales y no concesionales, acordes con los intereses de China, los BRICS y los países en desarrollo (MAGALHÃES, 2018). El pilar de la institucionalidad también tiene un plano político: el Foro de Cooperación al Desarrollo de Naciones Unidas (UNDCF, por sus siglas en inglés, desde 2006) y más específicamente la resucitada, desde 2009, Unidad de Cooperación Económica e Integración entre Países en Desarrollo de la UNCTAD (GOSOVIC, 2016), a las que se acaba de unir en abril de 2018, y desde el frente bilateral, la State International Development Cooperation Agency. De cualquier forma, el AIIB, como el Banco Mundial en el régimen internacional de la ayuda, va a ser el núcleo del primer pilar al que acompañarán los otros dos que van a conformar el trípode del nuevo régimen internacional de CSS, que será competitivo con el del CAD.

Según la teoría económica que sustenta el nuevo régimen internacional de CSS (la nueva economía estructural) ${ }^{21}$, el régimen internacional del CAD fracasó porque no hizo suficiente énfasis en ayudar a los países en desarrollo a superar sus cuellos de botella de infraestructura, y ello fue así porque la economía de la corriente principal (predicada por el FMI y Banco Mundial y los Bancos Regionales de Desarrollo) no le dio importancia a la transformación estructural, mientras que la ayuda condicionada del régimen del CAD (a cambios en las políticas económicas y reformas institucionales que interfirieron la soberanía nacional de los países en desarrollo) violó el principio de apropiación (según el cual la ayuda deber atenerse a las prioridades establecidas por los países beneficiarios) que este organismo se dedicó a predicar y sin el cual la ayuda, como se afirma en la Declaración de París, resulta ineficaz (LIN, WANG, 2017).

21 La teoría de la nueva economía estructural (LIN, 2012) asume el patrón difusionista del desarrollo a partir de la trayectoria en $\mathrm{V}$ invertida (flying geese pattern), según la cual China, en su proceso de graduación en desarrollo, reasignará las industrias más intensivas en mano de obra hacia otros países menos desarrollados, donde la inversión en infraestructuras permitirá capturar esa ventana de oportunidad por las ventajas de una mano de obra más barata, generando empleos, reduciendo la pobreza y ayudando así a subir por la escalera del desarrollo (a escalar la montaña) como hizo China en su historia reciente (LIN; WANG, 2017). Para una formalización de este modelo, que se basa en las ventajas comparativas dinámicas con CSS reforzada con IED, véase LU; LI (2010) y para la aproximación histórica al mismo el reciente ensayo de MISHRA (2018). 
El segundo pilar del nuevo régimen será el instrumento financiero de cooperación, el development compact y la financiación ampliada del desarrollo. El development compact es el concepto que da coherencia a la cooperación de India, y que ha ganado rápidamente aceptación en Naciones Unidas como nueva métrica (COSTA, XIAOJING, SHUAI, 2016), en la que se agrupan cinco ámbitos de actuación: comercio e inversión, tecnología, construcción de capacidades, financiación concesional (líneas de crédito) y subvenciones (CHATURVEDI, 2016; CHAKRABARTI, 2016; RIS, 2016a; FIDC/RIS/NeST, 2016). Por su parte, el esquema de financiación ampliada del desarrollo es la propuesta de China de cooperación para la transformación estructural, centrada en la inversión en infraestructuras, que tan buenos resultados le dio al gigante asiático en su cooperación con Japón o Alemania (LIN, WANG, 2017); este concepto, que ya se adelantó a la modernización de la AOD y al TOSSD (LIN, WANG, 2014, 2015), engloba la AOD y los Otros Flujos Oficiales del CAD (pero, al contrario que el TOSSD, no incluye gastos militares), les añade financiación oficial a tipos de interés de mercado por parte de entidades estatales, y la IED de origen público, los avales públicos para proyectos de desarrollo y el aporte público a las Alianzas Público-Privadas. Ambas propuestas (development compact y financiación ampliada del desarrollo) ya han ganado la guerra antes de la batalla, como muestra el intento de isomorfismo contable del CAD con su nuevo concepto transformista de TOSSD (supuestamente para medir la contribución de los países desarrollados y en desarrollo a la Agenda de Desarrollo Sostenible 2030), con la que se pretende hacer cambios dentro del régimen internacional de la ayuda para desactivar el cambio del régimen internacional de cooperación, una empresa cuyo éxito parece sumamente improbable (BESHARATI, 2017; CHATURVEDI, CHAKRABARTI, SHIVA, 2016).

Por último, el tercer pilar del nuevo régimen será el sistema de monitoreo y evaluación, que es, con diferencia, el que lleva más retraso de los tres en su construcción. De momento, vale decir que, al margen de las condiciones de posibilidad para crear una agencia china de cooperación que, contra lo que algunos pronosticaban (ZHANG, SMITH, 2017) se acaba de crear en abril de 2018 (la State Agency for International Development Cooperation, con un alto perfil), el AIIB (junto con el Fondo de la Ruta de la Seda y el New Development Bank de los BRICS) presionará a favor de una evaluación completa de la legitimidad y gobernanza de la ayuda internacional. Para ello será preciso crear una una ley, en la cual se establezcan, entre otros elementos, el sistema de monitoreo y evaluación de la ayuda para la necesaria transparencia y rendición de cuentas ante los ciudadanos 
chinos y la comunidad de desarrollo internacional (LIN; WANG, 2017). En todo caso, cabe prever que China instrumentalizará la demanda de evaluación por resultados, sobre la que presionan comunidades epistémicas como EvalPartners y los donantes del CAD con sus brazos financieros multilaterales y su sociedad civil organizada, para construir una práctica evaluativa comprensiva de lo que verdaderamente es la medida de éxito de las intervenciones de CSS (los objetivos últimos del bienestar, la autonomía nacional y colectiva y las metas de la agenda internacionalmente pactada en Naciones Unidas), en una difícil integración entre evaluaciones de proceso (con criterios pertinentes de eficiencia y gobernanza compartida) y evaluaciones de resultados (con criterios pertinentes de eficacia, impacto y sostenibilidad) (DOMÍNGUEZ, 2018).

De acuerdo a la teoría estructural de los cambios de régimen internacional, a medida que las relaciones de poder agregadas cambian también lo hacen los regímenes internacionales, de manera que cuando el poder total en el sistema internacional se dispersa (concentra), los regímenes internacionales se desmoronan (y el nuevo hegemón se desarrolla) (KEOHANE, NYE, 2011). Ello indica que, ante la crisis hegemónica de EEUU (SUBRAMANIAN, 2011; McCOY, 2017) y el imparable ascenso de China como la nueva potencia reguladora de la economía global (SPENCE, 2017), estamos a las puertas de una trasformación estructural en términos de las relaciones y límites competenciales entre diferentes organizaciones internacionales y nacionales, de la propia definición y objetivos del desarrollo, y de las estructuras de gobernanza de este campo de las relaciones internacionales (FEJERSKOV, 2016), en definitiva, ante un de cambio del régimen internacional en toda regla.

Dicho cambio, del régimen del CAD por el del régimen de CSS, tendrá lugar tras un período transitorio (y probablemente más breve de lo que muchos piensan) que podría denominarse multilateralismo competitivo (STUENKEL, 2017). Entonces se podrá discutir si este nuevo régimen liderado por China tiene el carácter de CSS que a fecha de 2016 transparentan los casi 100.000\$ millones de fondos de desarrollo puestos a disposición de los países del Sur por China, de acuerdo a un esquema regional articulado a sus diálogos estratégicos, con la novedad de los dos fondos multilaterales, el Fondo Climático Sur-Sur, por valor de 3.200\$ millones, y el Fondo de Cooperación Sur-Sur para la Agenda de Desarrollo Sostenible 2030, dotado con 2.000\$ millones (KAMAL; GALLAGHER, 2016). Y la razón de tal cuestionamiento es que China perderá la condición de país de ingreso medio-alto (se graduará en desarrollo convirtiéndose en un país desarrollado, según 
la terminología de los arquitectos del régimen internacional de la ayuda) no más allá de 2022 (LIN, 2017). Aunque para entonces todo el aparato conceptual y las métricas del CAD y del Banco Mundial con las que los países desarrollados han ejercido su hegemonía intelectual (GOSOVIC, 2000) probablemente será sometido a revisión de acuerdo a los principios y los intereses de China, y subsidiariamente a los de los demás BRICS y los países en desarrollo, recuperando, así, parte del tiempo perdido y de los contenidos de la agenda del NOEI.

\section{Referencias}

AMIN, Samir. The world without Bandung, or for a polycentric system with no hegemony. Inter-Asia Cultural Studies, vol. 17, n. 1, 2016, p. 7-11.

ANÓNIMO. Proposiciones para un nuevo orden económico internacional. Documento Provisional del Grupo Especial de Trabajo del Foro del Tercer Mundo. Nueva Sociedad, n. 21, 1975, p. 75-85.

ARNER, Douglas W.; SOARES, Andre. A Globalized Renminbi. Will It Reshape Latin America? Washington: Atlantic Council, Adrienne Arsht Latin American Center, 2016. ASEAN. Overview of ASEAN-China Dialogue Relations. ASEAN Secretariat Information Paper, 2017.

ASSIE-LUMUMBA, N'Dri Therese. Behind and beyond Bandung: historical and forwardlooking reflections on south-south cooperation. Bandung: Journal of the Global South, vol. 2, n. 11, 2015, p. 1-11.

AVENDANO, Rolando; MELGUIZO, Angel; MINER, Sean. Chinese FDI in Latin America:

New Trends with Global Implications. Atlantic Council, Adrienne Arsht Latin American Center, Washington, 2017.

BARAN, Paul A. La economía política del crecimiento. México: Fondo de Cultura Económica, 1975 (sobre la segunda edición en inglés de 1962).

BARBÉ, Esther. Cooperación y conflicto en las relaciones internacionales (La teoría del régimen internacional). Revista CIDOB d'Afers Internacionals, n. 17, 1989, p. 55-67.

BELL, Daniel A. The China Model. Political Meritocracy and the Limits of Democracy. New Jersey: Princenton University Press, 2015.

BODENHEIMER, Susanne. Dependency and Imperialism. NACLA Report on the Americas, vol. 4, n. 3, 1970, p. 18-27.

BERNAL-MEZA, Raúl. China and Latina America Relations: The Win-Win Rhetoric. Journal of China International Relations, Special Issue, 2016, p. 27-43.

BESHARATI, Neissan. New development finance should be TOSSD out of the window. SAIIA Policy Insights, n. 45, 2017. 
BORRÀS, J. Wang Huning, el intelectual más poderos de China. 2018. Disponível em: < https://www.esglobal.org/wang-huning-intelectual-mas-poderoso-china/ > . Acesso em: 16 de março de 2018.

BOYOU, Wen. China, India and the New International Order. China Report, vol. 29, n. 3, 1993, p. 285-298.

BURROWS, Mathiew J.; BOHL, David K.; MOYER, Jonathan D. Our World Transformed. Geopolitical Shocks and Risks. Washingto: Atlantic Council y Frederick S. Pardee Center for International Futures, 2017.

BYRES, Terence J. The White's Man Burden in a Neocolonial Setting. en BYRES, Terence J. (ed.), Foreing Resources and Economic Development. A Symposium of the Report of the Pearson Commission, Londres: Frank Cass, 1972, p. 77-116.

CALLAHAN, William A. China's “Asia Dream”: The Belt Road Initiative and the new regional order. Asian Journal of Comparative Politics, vol. 1, n. 3, 2016, p. 226-243.

CAREY, R.; XIAOYUN, L. China's Comprehensive Strategic and Cooperative Partnership with Africa. IDS Policy Briefing, n. 111, 2016.

CHAKRABARTI, Milindo. Development Compact - The Cornerstone of India's Development Cooperation: An "Externalities" Perspective. Forum for Indian Cooperation Policy Brief, n. 8, 2016.

CHAKRABARTI, Milindo. Global South rhetoric in India's policy projection. Third World Quarterly, vol. 38, n. 8, 2017, p. 1909-1920.

CHATURVEDI, Sachin. The Development Compact: A Theoretical Construct for SouthSouth Cooperation. RIS Discussion Paper, n. 203, 2016.

CHATURVEDI, Sachin; CHAKRABARTI, Milindo; SHIVA, Hemant. TOSSD: Southernisation of ODA. Forum for Indian Cooperation Policy Brief, n. 9, 2016.

CHATURVEDI, Sachin; MOHANTY, S.K. Indian Development Cooperation: A Theoretical and Institutional Framework. Forum for Indian Cooperation Policy Brief, n. 7, 2016.

CHIN, Helen; HE, Winnie. The Belt and Road Initiative: 65 Countries and Beyond. Hong Kong: Fung Business Intelligence Center, 2016.

CONNELLY, Marisella. China: de la diplomacia revolucionaria a la diplomacia de paz y desarrollo. Estudios de Asia y África, vol. 26, n. 2, 1991, p. 296-314.

CORNEJO, Romer. Confucianismo y desarrollo económico. Estudios de Asia y África, vol. 32, n. 3, 1997, p. 519-538.

CostA, Karin; XIAOJING, Mao; SHUAI, Yao. Mix and Match? How Countries Deliver Development Cooperation and Lessons for China. UNDP y Chinese Academy of International Trade and Economic Cooperation, 2016.

DASGUPTA, Chandrasekhar. Brief History of Panchsheel. Economic and Political Weekly, vol. 51, n. 1, 2016, p. 26-31. 
DIMAGGIO, Paul J.; POWELL, Walter. W. The Iron Cage Revisited: Institutional Isomorphism and Collective Rationality in Organizational Fields. American Sociological Review, vol. 48 n. 2, 1983, p. 147-160.

DIRMOSER, Dietmar. La Gran Marcha china hacia el oeste. El megaproyecto de la nueva Ruta de la Seda. Nueva Sociedad, n. 270, 2017, p. 27-38.

DOMÍNGUEZ, Rafael. Más allá de la ayuda: una nueva métrica de la AOD post-2015. Íconos. Revista de Ciencias Sociales, n. 47, 2013, p. 31-45.

DOMÍNGUEZ, Rafael. Perspectivas de la cooperación internacional y el desarrollo sostenible después de 2015. Revista Internacional de Cooperación y Desarrollo, vol. 1, n. 2, 2014, p. 5-32.

DOMÍNGUEZ, Rafael. En los pliegues de la historia: Cooperación Sur-Sur y procesos de integración en América Latina y el Caribe. Estudos Internacionais: Revista Relações Internacionais, vol. 4, n. 2, 2016a, p. 57-77.

DOMÍNGUEZ, Rafael. Cooperación financiera para el desarrollo, ADN de la Cooperación Sur-Sur. Revista Iberoamericana de Estudios del Desarrollo, vol. 5, n. 1, 2016b, p. 62-86.

DOMÍNGUEZ, Rafael. La Alianza para el Progreso. Aportes para una teoría crítica de la cooperación. En DOMÍNGUEZ, Rafael; RODRÍGUEZ ALBOR, Gustavo (eds.), Historia de la Cooperación Internacional desde una perspectiva crítica. Barranquilla: Editorial Uniautónoma, 2017a, p. 105-161.

DOMÍNGUEZ, Rafael. La Princesa y el Dragón: Cooperación China en América Latina y el Caribe. Revista Internacional de Cooperación y Desarrollo, vol. 4, n. 2, 2017b, p. 3-27. DOMÍNGUEZ, Rafael. Avances sobre el monitoreo y la evaluación en la Cooperación Sur-Sur como nuevo régimen internacional. Estado Abierto. Revista sobre el Estado, la administración y las políticas públicas, vol. 2, n. 2, 2018, p. 48-108.

DOMÍNGUEZ, Rafael; TEZANOS, Sergio. Donaciones y créditos concesionales: impacto en el desarrollo. Revista Española de Desarrollo y Cooperación, n. 29, 2012, p. 119-154.

ENFU, Chen; XIAOQUIN, Ding. A Theory of China's “Miracle”. Eight Principles of Contemporaty Chinese Political Economy. Monthly Review, vol. 68, n. 8, 2017. Disponível em: <https://monthlyreview.org/2017/01/01/a-theory-of-chinasmiracle/ > . Acesso em: 20 de octubro de 2017.

EYBEN, Rosalind. Struggles in Paris: The DAC and the Purposes of Development Aid. European Journal of Development Research, vol. 25, n. 1, 2013, p. 78-9.

FARRELL, Henry; NEWMANN, Abraham. The new interdependence approach: theroretical development and empirical demostration. Review of International Political Economy, vol. 23, n. 5, 2016, p. 713-736.

FEJERSKOV, Adam Moe. Understanding the nature of change: how institutional perspectives can inform contemporary studies of development. Third World Quarterly, vol. 37, n. 12,2016 , p. 2156-2175. 
FIDC/RIS/NeST. South-South Cooperation. Mapping New Frontiers, 2016. Disponível em: < http://ris.org.in/sites/default/files/pdf/SSC-12\%20Page \%20Brochure_2.pdf > . Acesso em: 20 de octubro de 2017.

FRENKEL, Alejandro. Los BRICS y el multilateralismo expansivo chino. Nueva Sociedad, septiembre 2017. Disponível em: < http://nuso.org/articulo/los-brics-yel-multilateralismo-expansivo-chino/ > . Acceso em: 20 de octubre de 2017.

FUES, Thomas. Is the romance of South-South cooperation coming to an end?. The Current Column, German Development Institute, 11 de septiembre de 2017.

GILLESPIE, Patrick. 11 countries sign TPP trade pact without the United States. 2018. Disponível em: < http://money.cnn.com/2018/03/08/news/economy/tpp-trumptariffs/index.html > . Acesso em: 16 de março de 2018.

GOSOVIC, Branislav. Global Intellectual Hegemony and the International Development Agenda. International Social Science Journal, vol. 52, n. 166, 2000, p. 447-456.

GOSOVIC, Branislav. The resurgence of South-South cooperation. Third World Quarterly, vol. 37, n. 4, 2016, p. 733-743.

GUERRERO, Dorothy. Chinese Investment in Europe in the Age of Brexit and Trump. TNI Working Papers, 2017.

HARRIS, Richard L.; ARIAS, Amando A. China's South-South Cooperation with Latin America and the Caribbean. Journal of Development Societies, vol. 32, n. 4, 2016, p. 508-556.

HENDERSON, Jeffrey; APPELBAUM, Richar P.; HO, Suet Y. Globalization with Chinese Characteristics. Externalization, Dynamics and Transformations. Development and Change, vol. 44, n. 6, 2013, p. 1221-1253.

HICKEL, Jason. The Death of International Development. Global Policy Journal, 2015. Disponível em: < http://www.globalpolicyjournal.com/blog/18/03/2015/deathinternational-development.dilemma-aid-reverse-how-poor-countries-develop-richcountries > . Acesso em: 20 de octubro de 2017.

HUTTON, Nicholas. The OEEC and the OECD : A Comparative Study. Millenium: Journal of International Studies, vol. 3, 1974, n. 3, p. 234-251.

IFA. Summit Declarations of Non-Aligned Movement (1961-2009). Kathmandu: Institute of Foreign Affairs, 2011.

KAMAL, Rohini; GALLAGHER, Kevin P. China goes global with development Banks. Bretton Woods Project, abril 2016.

KARATASLI, Sahan S.; KUMRAL, Sefika. Territorial Contradictions of the Rise of China. Geopolitics, Nationalism and Hegemony in Comparative-Historial Perspective. Journal of World-Systems Research, vol. 23, n. 1, 2017, p. 5-35.

KATZ, Claudio. Belicismo, globalismo y autoritarismo. La Haine, 2017. Disponível em: < https://www.lahaine.org/mundo.php/belicismo-globalismo-y-autoritarismo > . Acesso em: 20 de octubro de 2017. 
KELLOG, P. Geographies of capital accumulation: tracing the emergence of multi-polarity, 1980-2014. Research in Political Economy, n. 30, 2015, p. 259-294.

KEOHANE, Robert O. After Hegemony: Cooperation and Discord in the World Political Economy. Princeton, NJ: Princeton University Press, 1984.

KEOHANE, Robert O.; NYE, Joseph S. Between Centralization and Fragmentation: The Club Model of Multilateral Cooperation and Problems of Democratic Legitimacy. Faculty Research Working Paper J.F. Kennedy Harvard School of Government, n. 01-004, 2001.

KEOHANE, Robert O.; NYE, Joseph S. Power and Interdependence. Boston: Longman, Fourth Edition, 2011.

KOVRIG, Michel. Las idas y venidas de la Ruta de la Seda. Política Exterior, 19 de octubre de 2017. Disponível em: < http://www.politicaexterior.com/actualidad/las-idas-yvenidas-de-la-ruta-de-la-seda/ > . Acesso em: 20 de octubro de 2017.

KRASNER, Stephen. Structural causes and regime consequences: Regimes as intervening variables. International Organization, vol. 36, n. 2, 1982, p. 185-205.

LI, Xing. The Expansion of China's Global Hegemonic Strategy: Implications for Latin America. Journal of China International Relations, Special Issue, 2016, p. 1-26.

LIN, Justin Yifu. New Structural Economics. A Framework for Rethinking Development and Policy. Washington: The World Bank, 2012.

LIN, Justin Yifu. China's economic development and cultural reinassence in the multipolar growth world of the twenty-first century. China Economic Journal, vol. 6, n. 1, 2013, p. 1-11.

LIN, Justin Yifu. The rise of China and its implications for economics and other developing countries. Area Development and Policy, vol. 2, n. 2, 2017, p. 109-119.

LIN, Justin Yifu; WANG, Yan. China-Africa co-operation in estructural transformation: Ideas, opportunities and finances. WIDER Working Paper, n. 46, 2014.

LIN, Justin Yifu; WANG, Yan. China’s Contribution to Development Cooperation: Ideas Opportunities and Finances. FERDI Working Paper, n. 119, 2015.

LIN, Justin Yifu; WANG, Yan. Going Beyond Aid. Development Cooperation for Structural Tranformation. Cambridge: Cambridge University Press, 2017.

LIM, Alvin C.H. China’s “Belt and Road” and Southeast Asia: Challenges and Prospects. Jati. Journal of Southeast Asian Studies, vol. 20, n. 1, 2015, p. 3-15.

LU, Xiaodong; LI, Ronglin. South-South cooperation: is there a foundation in trade? Journal of Chinese Economic and Foreign Trade Studies, vol. 3, n. 3, 2010, p. 231-234.

LUIJKX, Willem; BENN, Julia. Emerging providers' international co-operation for development. OECD Development Co-operation Working Paper, n. 33, 2017.

MAGALHÃES, Diego Trindade d'Ávila, The globaliser dragon: how is China changing economic globalisation? Third World Quarterly, Early view, DOI: 10.1080/01436597.2018.1432352, 2018, p. 1-23. 
McCOY, Alfred W. In the Shadows of the American Century. The Rise and Decline of US Global Power, Chicago: Dispatch Books, 2017.

MEDINA, Romeo. Reunión Sur-Sur Beijing 1983. Estudios de Asia y África, vol. 18, n. 4, 1983, p. 672-684.

MELO, Hector; YOST, Israel. Funding the Empire. US Foreign Aid-Part 1. NACLA Report on the Americas, vol. 4, n. 2, 1970a, p. 1-13.

MELO, Hector; YOST, Israel. Funding the Empire. US Foreign Aid-Part 2 The Multinational Strategy. NACLA Report on the Americas, vol. 4, n. 3, 1970b, p. 1-17.

MINGH, Shi. Rusia y China: ¿aliados-rivales? Geopolítica de los acuerdos por el gas. Nueva Sociedad, n. 253, 2014, p. 177-186.

MISHRA, Pankaj. The Rise of China and the Fall of the "Free Trade" Myth. The New York Times Magazine. Disponível em: < https://www.nytimes.com/2018/02/07/ magazine/the-rise-of-china-and-the-fall-of-the-free-trade-myth.html > . Acesso em: 16 de março de 2018.

MONCADA, Mariola. Visión del mundo exterior de las cuatro generaciones de líderes políticos de la República Popular China: Evolución histórica y conceptual. Documentos CIDOB Asia, n. 27, 2011.

MORGENTHAU, Hans. The United Nations and China. International Studies, vol. 10, n. 1-2, 1968, p. 23-34.

MOURON, Fernando; URDINEZ, Francisco; SCHENONI, Luis. Sin espacio para todos: China y la competencia por el Sur. Revista CIDOB d'Afers Internacionals, n. 114, 2016, p. 17-39.

MUKHERJEE, Aditya. Da globalização colonial à globalização pós-colonial: o não alinhamiento e Cooperação Su-Sul. Austral: Revista Brasileira de Estratégia e Relações Internacionais, vol. 1, n. 2, 2012, p. 265-288.

NKRUMAH, Kwame. Neo-colonialism. The Last Stage of lmperialism. New York: International Publishers, 1966.

OECD-DAC. Inside the DAC. A Guide to the OECD Development Assistance Committee. París: OCDE, 2010.

OECD-DAC. The DAC Network on Development Evaluation - 30 years of strengthening learning in development. París: OCDE, 2013.

PARK, Jinman. Is the Chinese Government's Increase in Development Co-operation with Africa the Revival of Sinocentrism? Geopolitics, vol. 20, n. 3, 2016, p. 626-644.

PEREIRA, Analúcia D.; MEDEIROS, Klei. A emergência da periferia no sistema mundial: da Conferência de Bandung à Conferência de Buenos Aires (1955-1978). Austral: Revista Brasileira de Estratégia e Relações Internacionais, vol. 4, n. 7, 2015, p. 119-138. POGGETTI, Lucrezia. China's Charm Offensive in Eastern Europe Challenges EU Cohesion. 2017. Disponível em: < https://thediplomat.com/2017/11/chinas-charm-offensivein-eastern-europe-challenges-eu-cohesion/ > . Acesso: 20 de novembro de 2017. 
POZNANSKI, Kaziemierz. Confucian economics: how is Chinese thinking different? China Economic Journal, vol. 10, n. 3, 2017, p. 362-384.

RIS. South-South Cooperation 2016: Conference Proceedings. New Delhi, Research and Information System for Developing Countries (RIS), 2016a.

RIS. Resurging South. Stylized Facts, 2016b. Disponível em < http://ris.org.in/pdf/ FINAL \% 20SSC \% 20POLICY \% 20BRIEF \% 20for \% 20printer.pdf > . Acesso em: 20 de octubre de 2017.

ROCH, Eugenio A. China: la política de cooperación con el Tercer Mundo. Estudios de Asia y África, vol. 14, n. 3, 1980, p. 515-571.

SANTILLÁN, Gustavo. El Sueño Chino de Rejuvenecimiento Nacional: bases de formulación, dimensión interna y diálogo sinonorteamericano. Relaciones Internacionales, n. 53, 2017, p. 191-205.

SCOTT, Simon. The accidental birth of "official development assistance". OECD Development Co-operation Working Paper, n. 24, 2015.

SCOTT, Simon. The gran element method of measuring the concessionality of loans and debt relief. OECD Development Center Working Paper, n. 339, 2017.

SEN, Sunanda. The BRICS Initiatives Towards a New Financial Architecture: An Assessment with Some Proposals. RIS Discussion Paper, n. 205, 2016.

SESHADRI, V.S. Regional Comprehensive Economic Partnership Agreement: Need for a Strategy. RIS Discussion Paper, n. 209, 2017.

SINGH, Zorawar D. Limited Geopolitical Accommodation Benefits for India-China Relations. Economic and Political Weekly, vol. 51, n. 53, 2016, p. 10-12.

SINGH, Zorawar D. Locating the Belt and Road in China's Broader Policy Shifts. Economic and Political Weekly, vol. 52, n. 25/26, 2017a, p. 10-13.

SINGH, Zorawar D. India and China. A Stubborn Relationship. Economic and Political Weekly, vol. 52, n. 39, 2017b, p. 10-11.

SOGGE, David. Sistema de ayuda extranjera: ¿régimen o vehículo hegemónico? Relaciones Internacionales, n. 12, 2009, p. 11-31.

SOGGE, David. Los donantes se ayudan a sí mismos. Cuadernos 2015 y más, n. 6, 2015.

SOLÍS, Mireya. The new geopolitics of trade in Asia. 2017. Disponível em: < https:// www.brookings.edu/blog/order-from-chaos/2017/11/15/the-new-geopolitics-oftrade-in-asia/ > . Acesso: 20 de novembro de 2017.

SOUTO, Mariana. Los regímenes internacionales en tiempos de globalización. Revista Sociedad Global, vol. 3, n. 1, 2009, p. 31-42.

SPENCE, Michel. La nueva potencia reguladora de la economía global. 2017. Disponível em: < https://www.project-syndicate.org/commentary/china-in-the-global-economyby-michael-spence-2017-08/spanish?barrier = accessreg $>$. Acesso em: 20 de octubro de 2017. 
STEINBERG, Federico. Cooperación y conflicto en las relaciones internacionales. Revista Española de Ciencia Política, n. 18, 2008, p. 149-176.

STUENKEL, Oliver. New Development Banks as horizontal international bypasses: Towards a parallel order? American Journal of International Law, vol. 111, 2017, p. 236-240. SUBRAMANIAN, Arvind. Eclipse: Living in the Shadow of China's Economic Dominance. Washington: Peterson Institute for International Economics, 2011.

TERRILL, Ross et al. Xi Jinping's China Reinaissance. Historical Mission and Great Power Strategy. New York: CN Times Books, 2016.

TIEZZI, Shannon. The New Silk Road: China’s Marshall Plan?, 2014. Disponível em: < http://thediplomat.com/2014/11/the-new-silk-road-chinas-marshall-plan/ > . Acesso: 20 de octubro de 2017.

TODD, Emmanuel. Después del Imperio. Ensayo sobre la descomposición del sistema norteamericano. Madrid: Foca, 2003.

TOKATLIAN, Juan G.; PARDO, Rodrigo. La teoría de la interdependencia: ¿un paradigma alternativo al realismo? Estudios Internacionales, vol. 23, n. 91, 1990, p. 44-81.

UNITED NATIONS. Proceedings of the United Nations Conference on Trade and Development. Fourth Session, Nairobi, 5-31 May 1976. Volume I Report and Annexes. New York: United Nations, 1977.

UNITED NATIONS. Arusha Programme for Collective Self-Reliance and Framework for Negotiations. En Proceedings of the United Nations Conference on Trade and Development. Fifth Session, Manila, 7 May-3 June 1979. Volume I Report and Annexes. New York: United Nations, 1981, p. 127-177.

WHEELER SNOW, Lois. China's Foreign Trade and Aid. Journal of World Trade, vol. 11, n. 2, 1977, p. 101-120.

WONG, Erebus. et al. One Belt, One Road. China’s Strategy for a New Global Financial Order. Monthly Review, vol. 68, n. 8, 2017. Disponível em < https://monthlyreview. org/2017/01/01/one-belt-one-road/ > . Acesso: 20 de octubro de 2017.

WORLD BANK. Aid Architecture. An Overview of the Main Trends in Official Development Assistance Flows. Washington: World Bank, 2008.

XIAOPING, Deng. I Establishing a New International Order on the Five Principles of Peaceful Coexistence. China Report, vol. 30, n. 2, 1994, p. 267-269.

XIAOYU, Pu. Controversial Identity of a Rising China. Chinese Journal of International Politics, vol. 10, n. 2, 2017, p. 131-149.

XINHUA. Xi Jinping and his era. 2017. Disponível em: < http://news.xinhuanet.com/ english/2017-11/17/c_136758372.htm > . Acesso: 20 de novembro de 2017.

XUETONG, Yan. La competición entre China y Estados Unidos por el liderazgo mundial. Documentos CIDOB Asia, n. 28, 2013. 
XUETONG, Yan. From Keeping a Low Profile to Striving for Achievement. Chinese Journal of International Politics, vol. 7, n. 2, 2014, p. 153-184.

XUETONG, Yan. Political Leadership and Power Redistribution. Chinese Journal of International Politics, vol. 9, n. 1, 2016, p. 1-26.

XUETONG, Yan. Chinese Values vs. Liberalism: What Ideology Will Shape the International Normative Order? Chinese Journal of International Politics, vol. 11, n. 1, 2018, p. 1-22. YAHUDA, Michael. The Chinese View of a New World Order. Millenium: Journal of International Studies, vol. 7, n. 1, 1970, p. 1-19.

YAQING, Qin. Cultura y pensamiento global: una teoría china de las relaciones internacionales. Revista CIDOB d'Afers Internacionals, n. 100, 2012, p. 67-90.

YAQING, Qin. Continuity through Change: Background Knowledge and China's International Strategy. Chinese Journal of International Politics, vol. 7, n. 3, 2014, p. 285-314.

ZHENGQUING, Yuan; ZHIYONG, Li; XIAOFEI, Zhufu. China and the Remolding of International Human Rights Norms. Social Sciences in China, vol. 38, n. 3, 2017, p. 25-46.

ZHANG, Denghua; SMITH, Graeme. China's foreign aid system: structure, agencies, and identities. Third World Quarterly, vol. 38, n. 10, 2017, p. 2330-2346.

ZHISHANG, Chen. Rethinking on China's human rights ideology. International Critical Thought, vol. 1, n. 4, 2011, p. 408-415.

\section{Páginas web}

AIIB (Asian Infrastructure Investment Bank). 2018. < https://www.aiib.org/en/aboutaiib/governance/members-of-bank/index.html $>$.

Economy Watch. 1980. < http://www.economywatch.com/economic-statistics/economicindicators/GDP_PPP_US_Dollars/1980/ > 1980.

Economy Watch. 2017. < http://www.economywatch.com/economic-statistics/economicindicators/GDP_PPP_US_Dollars/2017/ > . 